\title{
NOTAS ACERCA DA SOCIOLOGIA DA PUNIÇÃO: UMA CONTRIBUIÇÃO PARA O DEBATE SOBRE A JUSTIÇA CRIMINAL NO BRASIL (1985-2002)
}

\section{Rodolfo Arruda Leite de Barros}

Bacharel em Direito (UNIVEM) e Filosofia (UNESP).

Mestrando em Ciências Sociais (UNESP).

RESUMO: O artigo traça as linhas gerais do recente debate sobre a Sociologia da Punição, para, em seguida, contrastar seus desdobramentos com os destaques principais na área de Justiça Criminal no Brasil. De um lado, toma-se como base a fundamentação teórica do autor britânico David Garland, que encontra formulação em sua obra Punishment and Modern Society. De outro, analisam-se as ocorrências na área da Justiça Criminal brasileira, visualizadas, sobretudo, nas Políticas de Segurança Pública, desenvolvidas no período denominado de Transição Democrática, reconstruído a partir de uma leitura de seus autores mais importantes. Ao sobrepor os dois eixos, intenta-se descobrir na Sociologia da Punição abordagens úteis aos problemas da Justiça Criminal no Brasil.

PALAVRAS-CHAVE: Sociologia da Punição. Justiça Criminal no Brasil. Transição Democrática. Políticas de Segurança Pública. 


\section{INTRODUÇÃO}

Nas últimas três décadas do século $X X$, tanto no Brasil como nos países em desenvolvimento, assistiu-se a um aumento vertiginoso nos índices de criminalidade urbana, sobretudo nas regiões metropolitanas industrializadas do mundo. Por sua vez, esse fenômeno gerou um crescimento correlativo de variadas formas de violência, nas mais diversas relações humanas, fato que impôs duros limites à implementação de garantias jurídicas e políticas que vinham sendo buscadas ao longo de diversas lutas sociais.

Ao lado deste diagnóstico negativo, as instituições tradicionalmente responsáveis pela garantia da lei, pela pacificação interna do Estado, pela contenção da violência em seus limites e pelo combate ao crime em suas diversas modalidades, tem se mostrado cada vez mais incapazes de responder satisfatoriamente aos desafios para os quais são chamadas, fato que tem sugerido fortes desconfianças acerca de sua legitimidade e sobre os limites de sua competência para tratar esses problemas.

No horizonte deste terreno duplamente desalentador, uma variedade de pesquisas, oriundas de diversas tradições teóricas, se apresentaram para investigar a forma de funcionamento das instituições da justiça criminal. Ao longo dos anos, os estudos mostram, de forma inequívoca, que as instituições de justiça criminal, ao contrário de contribuir para a diminuição da criminalidade e da violência, são em sua grande maioria, agentes que acabam por induzir, reproduzir e até mesmo institucionalizar formas de violências e desrespeito às leis.

Baseando-se nestas constatações, muitos autores chegaram ao convencimento da necessidade de se reconfigurar as lentes da análise e do funcionamento de entidades que convencionalmente respondem por esses domínios, tais como a instituição da Prisão, a Polícia e o Judiciário. Esse redirecionamento exigiu que se repensassem as categorias mais comuns que abordam o assunto, tais como os conceitos de Direito, Sociedade, Poder, Estado, etc. promovendo uma reabertura de discussões que envolvem o projeto da Modernidade como um todo. 
É neste contexto que emerge o projeto de uma Sociologia da Punição. Oriundo de um amplo debate da tradição britânica, que tem como destaques a Criminologia Crítica e uma forte tradição de uma Sociologia Institucional (Interacionismo Simbólico), ele tem como proposta reabrir questões que relacionam a punição com a sociedade.

De acordo com Garland (1990), nas sociedades modernas dos países desenvolvidos, cristalizou-se uma maneira técnica de pensar questões ligadas ao controle do crime. A punição, sob a vigência do projeto da modernidade inaugurado desde Beccaria, se orientou num procedimento de racionalização que apresenta soluções prontas, burocraticamente pré-elaborada. No momento em que a punição racionalizada perde as ligações com a sociedade, surge a oportunidade de examinar outros domínios que ficavam afastados, como a moral, a opinião pública, as questões econômicas.

De forma semelhante, no âmbito das criminologias americanas e britânicas, o abandono do paradigma etiológico, significou, da mesma forma, um encaminhamento em direção à Sociologia. Já existia, portanto, no plano da criminologia, uma reabertura das questões sobre o conceito de crime e a natureza do delito. A influência marxista, para a Criminologia Crítica, já orientará de forma fundamental um reencontro de sociólogos, juristas e criminólogos, todos interessados em determinar quais seriam então as novas mediações entre crime, sociedade e controle do crime.

Após esse breve percurso, nota-se que o paradigma vigente, portanto, se torna o da Reação Social. Não se estabelece mais os problemas da criminalidade apenas como desvios que devem ser contornados ou combatidos, mas procura-se investigar, principalmente, como a sociedade como um todo tem participação em todo o processo, desde o processo de criminalização até a forma da punição dos delitos. Nesse sentido, a Sociologia da Punição significa um aprofundamento desse projeto, tentando examinar o que as práticas punitivas têm a revelar sobre a própria sociedade, sobre nós mesmos. 


\section{NOTAS SOBRE O PROJETO DE UMA SOCIOLOGIA DA PUNIÇÃO}

No debate contemporâneo que envolve uma ampla discussão sobre Justiça Criminal, que se desenvolve nos países de tradição anglo-saxônica, o autor que formulará de forma explícita o termo Sociologia da Punição é David Garland. Ele é autor de uma trilogia: Punishment and Welfare, Punishment and Modern Society e Culture of Control. Do três, Punishment and Modern Society é a obra na qual se encontra a formulação teórica mais fundamentada.

Segundo Garland (1990), um ponto chave que inaugura a Sociologia da Punição é a recepção da obra do filósofo francês Michel Foucault, Vigiar e Punir (1975). Além desse marco teórico, tem-se a obra Punição e Estrutura Social (1939) dos autores integrantes da escola de Frankfurt, George Rusche e Otto Kirchheimer. Em comum, essas obras reabrem questões-chave que se encontram no intermédio entre delito e pena.

Apenas em caráter ilustrativo, passamos a enumerar algumas características e obras fundamentais desse novo espaço investigativo.

* Separar Pena e Delito (ou, pelo menos, estabelecer entre essa relação um percurso muito maior do que uma relação imediata como apresenta a cultura tradicional).

Este principio já vinha anunciado em muitos autores dispersos, mas encontra uma formulação mais contundente nas obra de Foucault e Rusche e Kirchheimer.

Rusche e Kirchheimer apontam:

Para adotar uma abordagem mais profícua para a sociologia dos sistemas penais, é necessário despir a instituição social da pena de seu viés ideológico e de seu escopo jurídico e, por fim, trabalhá-la a partir de suas verdadeiras relações. (Rusche e Kirchheimer, 1939, pág 19)

Foucault, em sentido semelhante:

Analisar os métodos punitivos não como simples conseqüências de regras de Direito, ou como indicadores de estruturas sociais; mas como técnicas que tem sua especificidade no campo mais geral dos outros processos de poder. Adotar em relação aos castigos a perspectiva da tática política. ( Foucault, 1975, pág 24) 
* Não tratar a Punição a partir de teorias sociológicas totalizadoras: ao contrário, reunir o maior número possível de abordagens de modo a adequar melhor ao objeto.

Como proposta, a Sociologia da Punição pode aproveitar diversas contribuições, de referenciais teóricos diferentes, tentando estabelecer uma compreensão maior acerca do fenômeno social da punição. Garland pontua:

Minha intenção é, portanto, trabalhar entre as diversas tradições teóricas existentes, não tratando-as como modelos rígidos, mas como fontes especificas de perspectivas e interpretações parciais. Meu método será investigar e identificar as questões distintivas de cada tradição e examinar o que elas têm a dizer sobre as fundações, funções e efeitos da punição; e como elas nos ajudam a enteder a punição hoje. (Garland, 1990, pág 15)

* Postular a natureza complexa da Punição: admiti-la como um processo amplo que incorpora inúmeros agentes e instituições, tempos e lugares diferentes, abarcando desde a produção de leis penais até a execução penal.

Punição é tomada aqui como o processo legal pelo qual o transgressor de uma lei penal é condenado e sancionado de acordo com categorias legais específicas e procedimentos próprios. Este processo é, em si mesmo, complexo e diferenciável, sendo composto por um interligado processo de produção de leis penais, de julgamentos, de sentenciamentos, de administração de penalidades. Ele envolve recortes discursivos, repertórios de sanções penais, instituições e agentes para reforçar estas sanções, retóricas de símbolos, figuras, imagens pelas quais 0 processo é representado em suas variadas audiências. (Garland, 1990, pág 17).

* Articular, ou rearticular os laços entre: Poder Político, Estrutura PolíticoJurídica e Sociedade: Estado, Direito, Punição e Cultura. Determinar o limite da participação do Estado na construção dos sistemas punitivos. Verificar quais outros elementos se inserem nesses fenômenos punitivos: elementos culturais, morais, sociais, científicos/tecnológicos, variantes econômicas, ordens simbólicas, 
racionalidades, etc. Em que medida o resultado é também limitado por decisões políticas e estratégias de controle.

* Como conseqüência destes procedimentos, criar um espaço próprio de reflexão para analisar a punição. A punição com relativa autonomia de ocorrência e merecedora de métodos próprios para sua observação.

Com base nestes destaques da Sociologia da Punição, passo a analisar o caso da Justiça Criminal Brasileira, tentando investigar, a partir deste pontos teóricos, quais as particularidades pátria nessa área.

\section{DESTAQUES DA JUSTIÇA CRIMINAL BRASILEIRA NO PERÍODO DA TRANSIÇÃO DEMOCRÁTICA.}

Num artigo acadêmico publicado na revista de sociologia Tempo Social, USP, intitulado "Insegurança versus direitos humanos: entre a lei e a ordem" o professor Sérgio Adorno ${ }^{1}$ faz uma análise do plano de Segurança Pública do governo FHC colocando, logo em primeiro plano, a necessidade de inserir essa reflexão no contexto maior da política e da sociedade brasileira.

O ponto de partida histórico-cronológico de sua análise (assim como dos outros pesquisadores elencandos neste artigo) é o período que se inicia em meados da década de oitenta (por volta de 1985) prosseguindo até os dias atuais, que é conhecido como o período da transição democrática ${ }^{2}$. Um dos assuntos mais importantes dessa discussão é a tese (defendida de forma unânime entre os especialistas da área) de que na transição entre o regime autoritário e a entrada na fase de consolidação democrática, tem-se um aumento significativo da violência e da criminalidade brasileira.

\footnotetext{
${ }^{1}$ A referência é: Tempo Social; Rev. Sociol. USP, S. Paulo, 11 (2); 129-153, out. 1999 (editado em fev. 2000). O texto referido está contido na idéia mais geral de um dossiê sobre o primeiro governo do presidente Fernando Henrique Cardoso.

2 Para um desdobramento mais aprofundado e conceitual da idéia de transição democrática no Brasil, ver o trabalho do Professor Paulo Sérgio Pinheiro. Sobre a o problema da violência no contexto dessa transição ver: Violência, crime e sistemas policiais em países de novas democracias: Tempo Social vol 9 (1), maio de 1997.
} 
A partir da década de oitenta, começa-se a formar um consenso único sobre o crescimento de inúmeros problemas ligados ao assunto, tanto do ponto de vista das estatísticas, como no plano das mentalidades das pessoas comuns, de que crimes como furtos, roubos, tráfico de drogas, assaltos, crime organizado, seqüestros, homicídios, agressões, violências etc., vêm aumentando de forma surpreendente, sobretudo nas metrópoles industrializadas do país.

Além disso, cresce o sentimento na população de medo e insegurança diante da explosão do crime e violência. Tais fenômenos acabam por gerar uma outra grave conseqüência: o sentimento de impunidade que se espalha em nossa sociedade, seguido de uma percepção do total fracasso das instituições políticas (entenda-se a justiça criminal como um todo: polícia, judiciário e sistema penitenciário) em conter, amenizar ou responder satisfatoriamente ao problema desse aumento incontornável e brutal da criminalidade e delinqüência no Brasil.

Ao lado deste diagnóstico pouco positivo, de acordo com os autores que investigam o problema da violência, no Brasil persiste um grave problema: em nosso país ainda não foi possível consolidar uma das características fundamentais de um Estado Democrático de Direito, que é o princípio do monopólio estatal legítimo do uso da violência física ${ }^{3}$.

O desafio central que essa constatação apresenta se refere à enorme dificuldade de conter os conflitos sociais, os distúrbios violentos e principalmente as inúmeras violações e desrespeitos aos direitos fundamentais dos cidadãos nos limites da soberania. Como conseqüência disso, existe uma forte disseminação, no seio de toda a população, da idéia de que os direitos civis fundamentais à cidadania constituem uma espécie de "privilégio" social que somente algumas camadas da população dispõem.

E essa percepção acaba por se bifurcar em duas soluções que compõem o cenário da discussão sobre segurança no Brasil: por um lado, a população sensível mais atingida pelo problema do aumento da violência sente-se fortemente inclinada a apoiar e legitimar medidas repressivas e violentas por parte do Estado e, de outro, essa percepção da limitação da ação estatal estimula um conjunto de iniciativas

\footnotetext{
${ }^{3}$ Este argumento é defendido pelo Prof. Sérgio Adorno, baseado nas formulações acerca do Estado Moderno encontradas em Max Weber.
} 
privadas $^{4}$ na tentativa de reagir e responder a estas questões. O aumento da segregação social, a supressão do espaço público, a guetificação e o fechamento em condomínios das classes médias e altas são fenômenos que vem se intensificando em nosso país. De certa forma, conforme estudos apontam, essas respostas alimentam uma espécie de ciclo vicioso de violência (como no caso da ação policial), aumentam a distância social entre os indivíduos (fomentando diversas formas de preconceitos) o que, por fim, parece contribuir pouco para uma orientação democrática.

A partir deste quadro geral dos problemas relativos à violência, criminalidade e insegurança no país, acreditamos ser mais fácil agora apresentar algumas características das políticas públicas de segurança que tomaram corpo no Brasil. A ilustração destas idéias aponta para um esboço do perfil da solução (ou resposta) que o estado brasileiro assumiu diante destes desafios e de como houve certo estrangulamento da discussão por conta dos efeitos dessas políticas.

\section{DESTAQUES DAS POLÍTICAS DE SEGURANÇA PÚBLICA NO BRASIL}

Diante deste diagnóstico geral, do contexto político e das transformações sociais por que passava (e ainda passa) a sociedade brasileira, alguns destaques sobre as políticas de segurança pública adotadas em nosso país podem nos servir como uma porta de entrada na discussão destes assuntos mais amplos sobre violência e criminalidade. De modo a enfaixar as diversas opiniões sobre o assunto, podemos simplificar em três grandes núcleos os problemas relativos à segurança pública que se desenvolveram durante a transição no Brasil:

1) um dos aspectos mais destacados entre os autores, consiste justamente no problema da herança autoritária que permanece nas instituições responsáveis por disseminar e garantir a eficácia e amplitude dos valores democráticos na sociedade brasileira. Há uma série de estudos mostrando que muitos órgãos encarregados de conter a violência e garantir o respeito

\footnotetext{
${ }^{4}$ Nesta especificidade, a obra de Teresa Caldeira, A Cidade de Muros, ilustra bem os impactos socioespaciais que se desenvolvem numa cidade abarcada por altos índices de criminalidade, violência e insegurança. Seu estudo também aponta um possível motivo pelo qual os discursos sobre os direitos humanos não obtiveram êxito no Brasil, e quais as conseqüências desse retrocesso em termos do debate sobre violência e criminalidade.
} 
e segurança aos cidadãos, acabam funcionando exatamente no sentido contrário em nosso país: tem-se no Brasil uma das polícias mais violenta do mundo, complementado por um sistema penitenciário reconhecido internacionalmente por suas condições sub-humanas ${ }^{5}$, que estimula e reproduz a população delinqüente.

2) um segundo aspecto dos elementos da política pública nacional aponta para uma reconfiguração da balança entre os espaços concedidos a dois grandes atores da justiça criminal: o Judiciário e a Força Policial. Enquanto as instituições judiciais permanecem cada vez mais abarrotadas de processo, morosas, ineficientes, deslegitimadas, com carências de recursos materiais e humanos, assumindo uma postura afastada e alheia aos desdobramentos problemáticos na esfera criminal, a força policial tem sido uma resposta recorrente, o que tem aumentado tanto o número de seu contigente tanto quanto a sua atuação nos conflitos de ordem pública. Tal direcionamento significa dizer que o Brasil vem optando (o que está de acordo com a sua tradição autoritária) por investir em soluções de cunho repressivo, paliativas e imediatas, por meio de controle policial, do que em instituições que estimulem a construção de uma ordem democrática, ou mesmo noções de direito e cidadania, tais como formas pacíficas de resolução de conflito, instituições jurídicas, educacionais, e demais formas de apoio social para diminuir a gravidade destes conflitos ${ }^{6}$.

5 A respeito destas afirmações, basta apontar dados apresentados por Paulo Sérgio Pinheiro, no artigo recém referido, comparando a atividade da polícia brasileira com a americana: "Em 1992, a polícia militar (brasileira) matou 1470 civis em São Paulo, enquanto a de New York matou 27 naquele mesmo ano." No tocante ao sistema penitenciário, a comparação é dispensada por conta do próprio consenso caricatural que se desenvolveu no país com proliferação de fatos trágicos, massacres e rebeliões que são amplificados cotidianamente nas mídias do país e até mesmo com livros como A Estação Carandiru, de Draúzio Varela. Diante deste aspecto mais específico, que mistura a análise do drama da justiça criminal no Brasil com relação aos meios de comunicação e informação do país já existe bibliografia a respeito: vide Nilo Batista, Mídia e Sistema Penal.

${ }^{6}$ Esta faceta da Política de Segurança Pública em nosso país não é privilégio do Brasil. Atualmente, no debate sobre os mesmos problemas em países de Primeiro Mundo (tais como EUA, Inglaterra, França e Alemanha) tem-se visto uma abordagem que contrapõe dois movimentos simultâneos e interligados: 1ㅇ. A retirada das políticas do Estado do bem-estar social (Welfare State), que diminui drasticamente os apoios sociais aos mais desfavorecidos (escolas, hospitais, garantias de trabalho, auxílios famílias, etc); $2^{\circ}$. Ao lado de um recrudescimento das ações policiais e repressivas na esfera pública que combatem os meios alternativos de sobrevivência e pequenos delitos na ordem social. O sociólogo francês Loïc Wacquant sintetiza este percurso como a transição do antigo Estado Social para um novo Estado Penal. Para aprofundar essa questões: As Prisões da Miséria e Punir os Pobres: a nova gestão da miséria nos Estados Unidos, ambos de sua autoria. 
3) por fim, outra questão a ser destacada é a dificuldade existente no trato com problemas penais específicos, como o controle da violência e da criminalidade, que acabam por sofrer fortes influências da esfera política, até mesmo de viés eleitoral. Há um consenso entre políticos de todas as posições de que abrir mão destas medidas autoritário-repressivas gera, incondicionalmente, um custo político negativo capaz de rebaixar qualquer projeto administrativo. Assim, como conseqüência, permanece entre partidos de direita e esquerda um estranho consenso, uma espécie de vulgata geral de como tratar estes assuntos ${ }^{7}$.

Com base nesses destaques, resulta claro que os problemas ligados à segurança e ao controle de criminalidade foram caminhando para uma situação de profundo desalento e sentimento de impossibilidade de tratamento dessas questões no país. O espaço cada vez menor para a comunicação, a mediação e conciliação entre os atores envolvidos nesta questão, insinua não conseguir escapar de uma reação violenta, o que acaba por realimentar todo o sistema novamente.

A questão que parece surgir, ao final deste percurso, de forma quase inevitável é: será que estamos mesmo diante de um caso intratável? Será mesmo que se trata de um processo desencadeado de forma irreversível, que exige dos dois lados reações violentas? Mais especificamente, o Brasil não poderia ter respondido de forma diferente a estas questões que envolvem violência e criminalidade?

\section{CONSIDERAÇÕES FINAIS}

Ao final deste percurso, que tentou em alguma medida discorrer sobre as várias discussões sobre o crime, violência e políticas de segurança, utilizando a contribuição da Sociologia da Punição, bem como apontar o panorama atual no qual esses debates se encontram nos países hegemônicos, resta ainda retomar a posição do Brasil diante desses desdobramentos. Logo de início, assumimos a posição de que essas discussões são absolutamente pertinentes para 0 nosso

7 O destaque em nosso país no tocante a este assunto é o caso mais específicos das Polícias Estaduais. Por conta de permanecerem hierarquicamente determinadas pelos governos estaduais (e fora de uma 
contexto nacional, uma vez que essas idéias, conceitos e propostas que estão em debate, têm como destino provável a propagação e transformação em práticas e ações sociais, que não estão circunscritas em limites políticos de soberania, nem aos países de primeiro mundo.

No caso brasileiro, muitos autores ${ }^{8}$ têm sugerido que devemos tomar um cuidado redobrado perante estas discussões, pois historicamente nosso país possui uma situação muito sensível de desigualdades sociais, miséria e violência. Soma-se ainda um passado colonial escravista e uma posição periférica no atual capitalismo globalizado, que faz com que conflitos sociais graves sejam tratados como problemas de ordem criminal. Temos, portanto, que encontrar uma participação desse debate sobre a Justiça Criminal que esteja atenta para a nossa condição interna (social, histórica e política) e evitarmos, igualmente, o emprego de soluções fáceis e injustas que são propagadas como novos modelos de renovação.

\section{REFERÊNCIAS BIBLIOGRÁFICAS}

BARATTA, Alessandro. Criminologia Critica e Critica do Direito Penal: Introdução à Sociologia do Direito Penal. Tradução Juarez Soares Cirino, 2ª edição, Editora Freitas Bastos, Rio de Janeiro, 1999.

BECCARIA, Cesare. Dos Delitos e das Penas. Tradução: Lucia Guidicini, 2ª edição. São Paulo, Martins Fontes, 1997.

CARRANZA, Elias (coordinador) Justiça Penal y Sobrepoblacíon Penitenciaria: Respuestas Possibles. ILANUD, México, Siglo Vientiuno Editores, 2001.

FOUCAULT, Michel. Vigiar e Punir. Tradução Raquel Ramalhete. 21a edição. Petrópolis: Editora Vozes, 1999.

GARLAND, David. Punishment and Modern Society: a study in social theory. Chicago: The University of Chicago Press, 1990.

RUSCHE e KIRCHHEIMER, Georg e Otto. Punição e Estrutura Social. Tradução Gizlene Neder, $2^{a}$ edição, Editora Revan, Rio de Janeiro, 2002.

PINHEIRO, Paulo Sérgio (org.). Democracia, Violência e Injustiça: O não-Estado de Direito na América Latina. Paz e Terra, São Paulo, 2000.

orientação mais geral, talvez federal; e racional de um projeto democrático), a atuação destas entidades está geralmente mais sensível a variações e articulações políticas mais imediatas. língua.

${ }^{8}$ Loïc Wacquant é um deles, no prefácio ao seu livro "As prisões da Miséria”, em tradução para nossa 
WACQUANT, Loïc. As Prisões da Miséria. Tradução André Telles. Rio de Janeiro: Jorge Zahar Editor, 2001.

Punir os Pobres: a nova gestão da miséria nos Estados Unidos. Rio de Janeiro: Freitas Bastos Editora, 1998.

\section{Artigos}

ALEXANDER, Jeffrey. O novo movimento teórico. R.B.C.S. n4 vol 2 jun de 1987.

CHRISTIE, Nils. Control de la delincuencia em europa y norteamerica: ejemplos que no deve seguirse. ILANUD, México, in: Justiça Penal y Sobrepoblacion Penitenciaria.

GARLAND, David. The meaning of mass imprisonment. London: Sages Editor, 1998 Review Punishment and Society. Vol, iii, $\mathrm{n}^{\circ} 2$. 